\title{
Geometric considerations of polar mesospheric summer echoes in tilted beams using coherent radar imaging
}

\author{
S. Sommer, G. Stober, J. L. Chau, and R. Latteck \\ Leibniz Institute of Atmospheric Physics at the University of Rostock, Schlossstr. 6, 18225 Kühlungsborn, Germany \\ Correspondence to: S. Sommer (sommer@iap-kborn.de)
}

Received: 17 December 2013 - Revised: 5 May 2014 - Accepted: 7 May 2014 - Published: 10 November 2014

\begin{abstract}
We present observations of polar mesospheric summer echoes (PMSE) using the Middle Atmosphere Alomar Radar System in Northern Norway $\left(69.30^{\circ} \mathrm{N}, 16.04^{\circ} \mathrm{E}\right)$. The radar is able to resolve PMSE at high spatial and temporal resolution and to perform pulse-to-pulse beam steering. In this experiment, 81 oblique beam directions were used with off-zenith angles up to $25^{\circ}$. For each beam pointing direction and range gate, coherent radar imaging was applied to determine the mean backscatter location. The location of the mean scatterer in the beam volume was calculated by the deviation from the nominal off-zenith angle of the brightest pixel. It shows that in tilted beams with an off-zenith angle greater than $5^{\circ}$, structures appear at the altitudinal edges of the PMSE layer. Our results indicate that the mean influence of the location of the maximum depends on the tilt of the beam and on the observed area of the PMSE layer. At the upper/lower edge of the PMSE layer, the mean backscatter has a greater/smaller off-zenith angle than the nominal offzenith angle. This effect intensifies with greater off-zenith beam pointing direction, so the beam filling factor plays an important role in the observation of PMSE layers for oblique beams.
\end{abstract}

\section{Introduction}

Strong VHF backscatter at mesospheric heights in polar regions were described by Ecklund and Balsley (1981) for the first time. As these echoes occur only during the summer months, they were named polar mesospheric summer echoes (PMSE). PMSE are caused by inhomogeneities in the electron density of a size comparable to the radar Bragg wave length ( $3 \mathrm{~m}$ at $50 \mathrm{MHz}$ radar frequency) in the presence of negatively charged aerosol particles. Different as- pects of PMSE have been studied with radars around $50 \mathrm{MHz}$ since their first observation, in particular the spectral width (Czechowsky and Rüster, 1997; Blix, 1999) or aspect sensitivity (Röttger and Vincent, 1978; Hocking et al., 1986) to understand the formation of these echoes. A review of the understanding of PMSE was done by Rapp and Lübken (2004), where the formation was explained by the presence of heavy charged ice particles. These ice particles lead to a significantly reduced electron diffusivity and explain the existence of PMSE in the presence of neutral air turbulence. This widely accepted theory explains the overall formation, but still the inner structure of the PMSE is mostly unknown. The limiting factor of the observation of the small scale structures is the relatively wide beam width, so interferometric techniques has been applied to gain insight into finer structures of PMSE.

In the last two decades, imaging methods developed for astronomical applications have been applied to atmospheric studies (Kudeki and Sürücü, 1991; Hysell and Chau, 2006). Together with flexible radar systems with interferometric capabilities, in-beam estimates have been done with different radars (Yu et al., 2001; Chilson et al., 2002; Chen et al., 2004; Sommer et al., 2013) to investigate PMSE. Coherent Radar Imaging (CRI) of PMSE has been usually applied with a vertical radar beam and method called Capon (e.g., Palmer et al., 1998). CRI weights the signal of several spatially separated receivers to resolve different backscatter locations within the beam volume. In the last few years, multiple beam experiments were combined with CRI to understand PMSE (Chen et al., 2008), to improve wind measurements (Sureshbabu et al., 2013) and to measure aspect sensitivity in the troposphere (Chen and Furumoto, 2013). The combination of multiple beam experiments with CRI allows to cover a large area at a high angular resolution. 

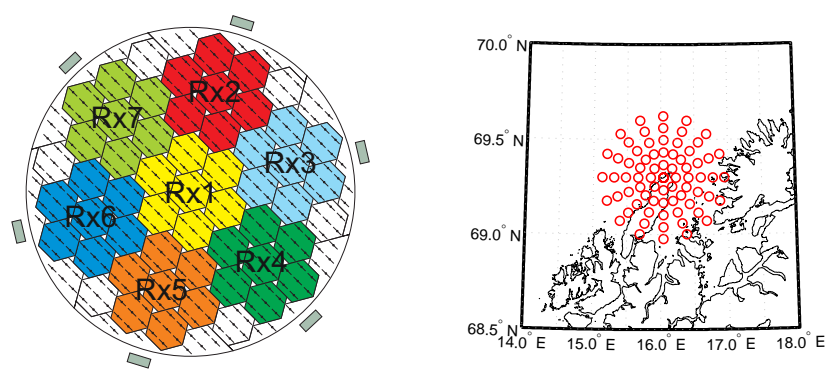

Figure 1. Left: Sketch of the antenna array. The 7 anemones indicated by different colors were used for reception. Right: Beam pointing directions of the CRI experiment setup. The black lines indicate the coast of Northern Norway, the red circles indicate the areas illuminated by the radar beams at about $85 \mathrm{~km}$ altitude.

In this study we present results obtained with the Middle Atmosphere Alomar Radar System (MAARSY) at Andøya in Northern Norway $\left(69.30^{\circ} \mathrm{N}, 16.04^{\circ} \mathrm{E}\right)$. The purpose of MAARSY is to investigate the dynamics of the mesosphere by studying wind and waves on a high spatial and temporal resolution and also the inner structure of PMSE, such as thin layers, that cannot be resolved by standard measurement techniques. For example, PMSE can be used as a tracer for wind measurements. In order to improve the derivation of gravity wave parameter out of wind measurements (Stober et al., 2012), the experiment should have a better spatial resolution. We have used MAARSY with a vertical and several oblique beams and applied CRI for different range gates and beam pointing directions. This allows us to determine the fine structure of PMSE in the vertical as well as in the oblique beams and estimate the deviation of the mean scatterer from the beam pointing direction.

\section{Experimental configuration}

MAARSY is a powerful tool to observe the troposphere up to the mesosphere at polar latitudes. It employs an active phased array antenna system at $53.5 \mathrm{MHz}$ consisting of 433 linear polarized Yagi antennas arranged in a circular shape with a diameter of $90 \mathrm{~m}$. The system reaches a half power beam width of $3.6^{\circ}$ and yields a peak power of about $800 \mathrm{~kW}$. It has pulse-to-pulse beam steering capabilities with 16 receiving channels allowing the observations of PMSE at high spatial and temporal resolutions. For further system descriptions, see Latteck et al. (2012).

The flexible setup of MAARSY can be used to assign receiving channels to different antenna sub-arrays allowing different baseline lengths and directions. The smallest subarray consists of seven antennas in the shape of a hexagon. Seven adjacent hexagons can be combined to an antenna substructure consisting of 49 single antennas called anemone. A sketch of the locations of the seven possible anemones is shown in Fig. 1 (left panel). MAARSY can be used for in-
Table 1. Experiment parameters

\begin{tabular}{ll}
\hline Parameter & Value \\
\hline PRF & $1250 \mathrm{~Hz}$ \\
Pulse length & $1 \mu \mathrm{s}$ \\
Code & 16 -bit complementary code \\
Sampling range & $75-111 \mathrm{~km}$ \\
Range resolution & $150 \mathrm{~m}$ \\
Data points & 256 \\
Nyquist frequency & $34.72 \mathrm{~Hz}$ \\
\hline
\end{tabular}

terferometry and imaging experiments by selecting up to 16 receiving channels out of the 55 hexagons or 7 anomenes, revealing information within the beam volume. In this experiment, MAARSY transmitted with the whole array and 7 anemones were used for reception. These seven receiving channels have been phase calibrated using radio sources as described in Chau et al. (2013).

During the PMSE season in summer 2012, MAARSY was operated in a multi-beam mode using 81 different beam directions. In this experiment, 16 azimuth angles from 0 to $360^{\circ}$ with an azimuthal step width of $22.5^{\circ}$ and an off-zenith step width of $5^{\circ}$ from 0 to $25^{\circ}$ were used. The experiment was divided into sub-experiments, each consisting of 9 beam pointing directions and including the vertical beam. During a sub-experiment, the beam pointing position was changed along a straight line on a pulse-to-pulse basis. The coherent integration time for each sub-experiment was $7.3 \mathrm{~s}$ and the whole sequence took $2.4 \mathrm{~min}$ (including sub-experiments probing the troposphere and therefore not used here). The beam pointing directions are visualized in Fig. 1 (right panel) where the red circles indicate the areas illuminated by the radar beams at about $85 \mathrm{~km}$ altitude. The sampling range was from 75 to $111 \mathrm{~km}$ with a range resolution of $150 \mathrm{~m}$. Additional experiment parameters are summarized in Table 1.

\section{Coherent radar imaging (CRI)}

Radar systems with multiple receiver channels attached to different spatially separated antennas can be used to perform interferometric experiments. The first basic interferometric experiments were performed by Farley et al. (1981) and Kudeki et al. (1981). This was later generalized for more receivers and baselines (Kudeki and Sürücü, 1991). Since the seminal paper by Woodman (1997), the technique is called coherent radar imaging. CRI allows to process the data in a way to derive a finer angular resolution within the illuminated beam volume. Several inversion algorithms can be used, such as Capon (Palmer et al., 1998), Maximum Entropy (MaxEnt) (Hysell and Chau, 2006) or Compressed Sensing (Harding and Milla, 2013). Yu et al. (2000) showed that the results with Capon are comparable to MaxEnt in high signalto-noise-ratio (SNR) cases, and are computational faster. 

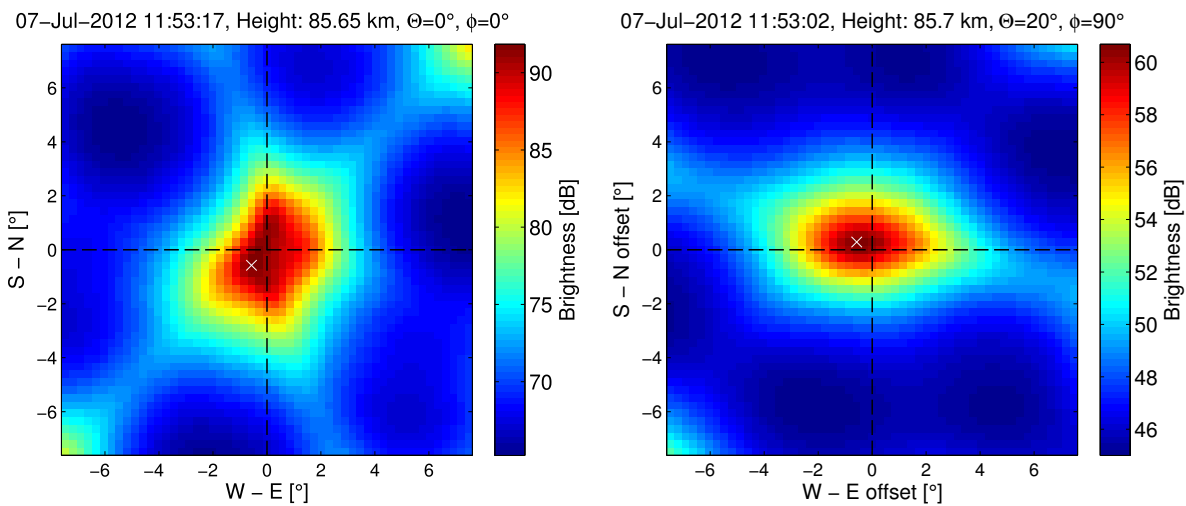

Figure 2. Brightness distribution of the zenith beam and a beam tilted $20^{\circ}$ off-zenith and $\phi=90^{\circ}$ using Capon's method in one range gate. The color coded brightness shows a superposition of the echo and the hexagonal receiving structure due to the alignment of the sub arrays. Furthermore, aliasing due to phase ambiguity can be seen at the outer edges of figures.

However, for lower SNR, MaxEnt gives better results at the expense of significantly higher processing time. Another possible algorithm is the Fourier-based algorithm (Palmer et al., 1998), but it results in a much broader brightness distributions than Capon's algorithm. In this work we present results using Capon's method.

This method makes use of visibility data $R_{i j}$ of $n$ spatially separated antennas $i$ and $j$. The visibility data is obtained from the normalized cross-correlation estimation:

$$
R_{i j}(t)=\frac{\left\langle v_{i}(t) v_{j}^{\star}(t)\right\rangle}{\sqrt{\left\langle\left|v_{i}(t)\right|^{2}\right\rangle\left\langle\left|v_{j}(t)\right|^{2}\right\rangle}},
$$

where $v$ are the complex voltage samples, $|\ldots|$ is the absolute value of the complex data and $\langle\ldots\rangle$ denotes the time average. This can be done for all receiver pairs and $R_{i j}$ can be arranged in a matrix, containing the visibility data

$\mathbf{R}(t)=\left[\begin{array}{ccc}R_{11}(t) & \ldots & R_{1 n}(t) \\ R_{21}(t) & \ldots & R_{2 n}(t) \\ \vdots & & \vdots \\ R_{n 1}(t) & \ldots & R_{n n}(t)\end{array}\right]$.

The resulting brightness distribution is

$\mathbf{B}_{c}(t, \boldsymbol{k})=\frac{1}{\boldsymbol{e}^{\dagger} \mathbf{R}^{-1} \boldsymbol{e}}$

with

$\boldsymbol{e}=\left[\begin{array}{c}e^{j k \cdot D_{1}} \\ e^{j k \cdot D_{2}} \\ e^{j k \cdot D_{3}} \\ \vdots \\ e^{j k \cdot D_{n}}\end{array}\right]$,

where $\boldsymbol{k}$ represents the wavenumber vector and $\boldsymbol{D}_{i}$ the distance vector in meters of the receiver $i$ with respect to the origin, $t$ is the time, $\boldsymbol{e}^{\dagger}$ denotes the conjugate transpose of $\boldsymbol{e}$, and $\mathbf{R}^{-1}$ is the inverse of the matrix $\mathbf{R}$.

Capon's algorithm does not consider the beam pattern, neither during transmission nor reception. As Capon's algorithm cannot contain a priori information, the beam weighting effects cannot be removed easily (Hysell and Chau, 2006). An example of the beam weighting effect on data is shown in Fig. 2 for the brightness in a vertical and in a $20^{\circ}$ offzenith beam. Due to aliasing, the pattern is repeated which can be seen at the corners of Fig. 2 (left panel). The effect of the antenna pattern of the transmitting and receiving beams are qualitatively in good agreement with the theoretical antenna pattern. Differences are attributed to the integration time used. Trying to remove the beam pattern afterwards may lead to an overestimation at the image periphery. This happens because it implies dividing by small numbers at the outer edges of the beam pattern.

However, the resulting brightness, i.e. the antenna pattern plus PMSE brightness, can be measured. From this brightness we can estimate the deviations of echo center from the beam pointing direction. For our analysis below, we selected the brightest pixel to be the mean echo center.

\section{Results}

To avoid the analysis of low SNR data, we set the threshold for the detection of PMSE to a SNR of $8 \mathrm{~dB}$. When the signal becomes noisy outside a PMSE layer due to the cosmic background, the mean scatter location is randomly distributed. Most of the time, more than one center of brightness appear in these noisy images.

The range-time-intensity (RTI) plots of the SNR for one day using the zenith and a $25^{\circ}$ off-zenith beam pointing northward $\left(\phi=90^{\circ}\right)$ are shown in Fig. 3. PMSE occur in the altitudinal interval of $80-90 \mathrm{~km}$, viz. for oblique beams, these altitudes corresponds to ranges of $88-100 \mathrm{~km}$ in a $25^{\circ}$ 


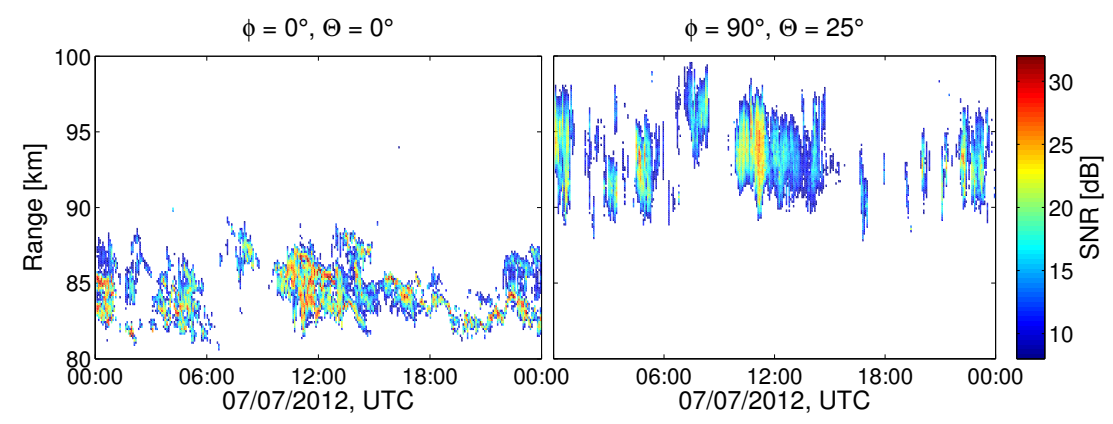

Figure 3. Range-time-intensity plot of PMSE occurring on 07 July 2012 in the zenith beam (left) and a beam tilted $25^{\circ}$ off-zenith (right). Color coded is the SNR, whereas only a SNR greater than $8 \mathrm{~dB}$ is displayed. The PMSE observed by the zenith beam occur in altitudes between about 80 and $90 \mathrm{~km}$, but appear at longer ranges in the tilted beam.

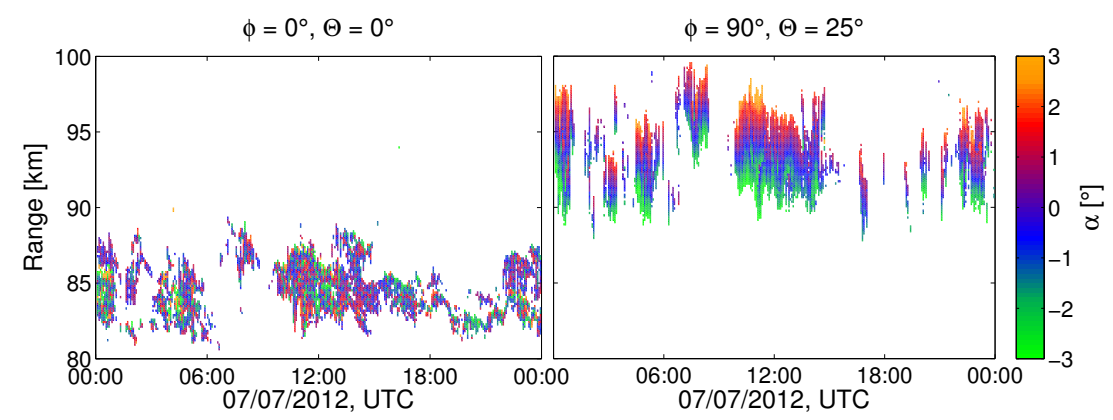

Figure 4. Deviation of the brightness peak from the beam pointing directions. Zenith (left) and $25^{\circ}$ off-zenith (right). The echo center is determined from brightest pixel. In the tilted beam the mean center deviates significantly from the pointing directions.

off-zenith beam. Comparing both RTI plots, it can be seen that the PMSE layer occurs in the tilted beam (right panel) at a longer and wider range than in the zenith beam (left panel), as expected. Besides, the two layers observed around 12:00 UTC in the vertical beam were not detected by the tilted beams.

The brightness for each range gate and pointing direction was gridded with a meridional and zonal step width of $0.01 \mathrm{rad}$. Next, the off-zenith angles $\alpha$ for the brightest pixel was calculated. The results for the zenith beam and the offzenith beam using the brightest pixel are shown for one day in Fig. 4. For a vertical beam, shown in the left panel of Fig. 4, the deviation is calculated with respect to the swivel direction. Deviations up to $\pm 3^{\circ}$ occur, but no pattern with the same direction of the deviation can be identified. Therefore we do not see evidence of tilted layers during the time of our observation.

In the right panel of Fig. 4, the deviation of the mean backscatter from the nominal beam pointing angle $25^{\circ}$ off-zenith is shown. It can be seen that deviations away from/towards the zenith (positive/negative values) occur in the upper/lower part of the PMSE layer. In between, the offzenith angle of the mean backscatter location is almost the same as the nominal beam pointing angle. Comparing this with the SNR of the range gate, especially for the large offzenith angles, the large deviations belong to low SNR values resulting from a low beam filling factor. Higher SNR values occur mostly in the middle of the PMSE layer, where the deviations from the nominal pointing directions are small and the beam volume appears to be homogeneously filled.

In Figs. 5 and 6 a swivel from North to South and East to West, respectively, is shown for the same date. Greater offzenith pointing beams show deviations of echo centers from the beam directions and such deviations emerge at the outer parts of the PMSE layer. Moreover, sub-structures indicated by the deviations of echo centers appear in some beams with $\Theta \geq 10^{\circ}$. More than one layer can be seen in tilted beams in contrast to the RTI plots. An example for this occurs at about 12:00 UTC in the beam pointing towards $\phi=90^{\circ}$ with $\Theta \geq$ $10^{\circ}$. From the SNR plot in Fig. 3 (right panel), the PMSE appears to consist of one thick layer, however two layers are visible after the CRI analysis (see Fig. 5). Using CRI, the two layers observed in the vertical beam (left panel of Fig. 3) can now be observed in the tilted beams.

MAARSY's half power beam width of $3.6^{\circ}$ corresponds to a horizontal extension of $5 \mathrm{~km}$ at $80 \mathrm{~km}$ altitude, a titled beam pointing $25^{\circ}$ off-zenith spans a height of $2.4 \mathrm{~km}$. If the beam volume is inhomogeneously filled with PMSE, the mean backscatter location shifts toward the filled part of the beam volume. Due to the larger height coverage at great offzenith angles, the beam volume is only partly filled at the outer areas of the PMSE layer. Therefore in the upper/lower 

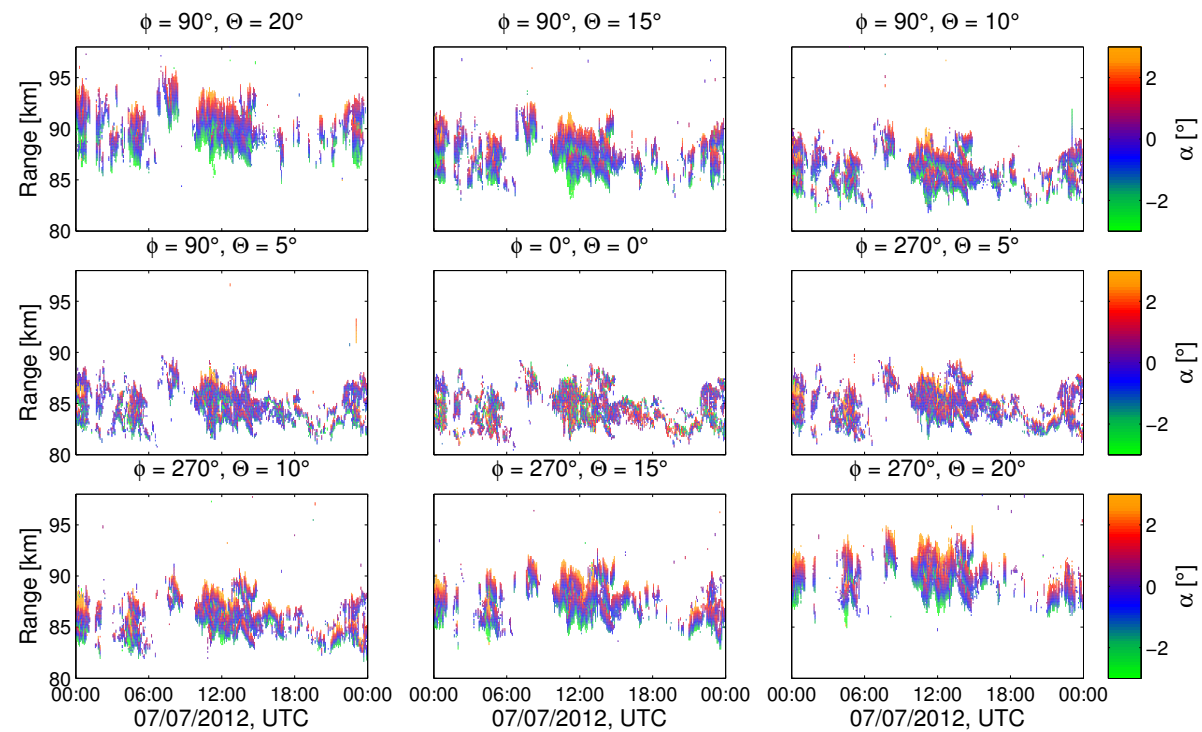

Figure 5. Similar to Fig. 4, but showing nine beams from North to South with different off-zenith angles.
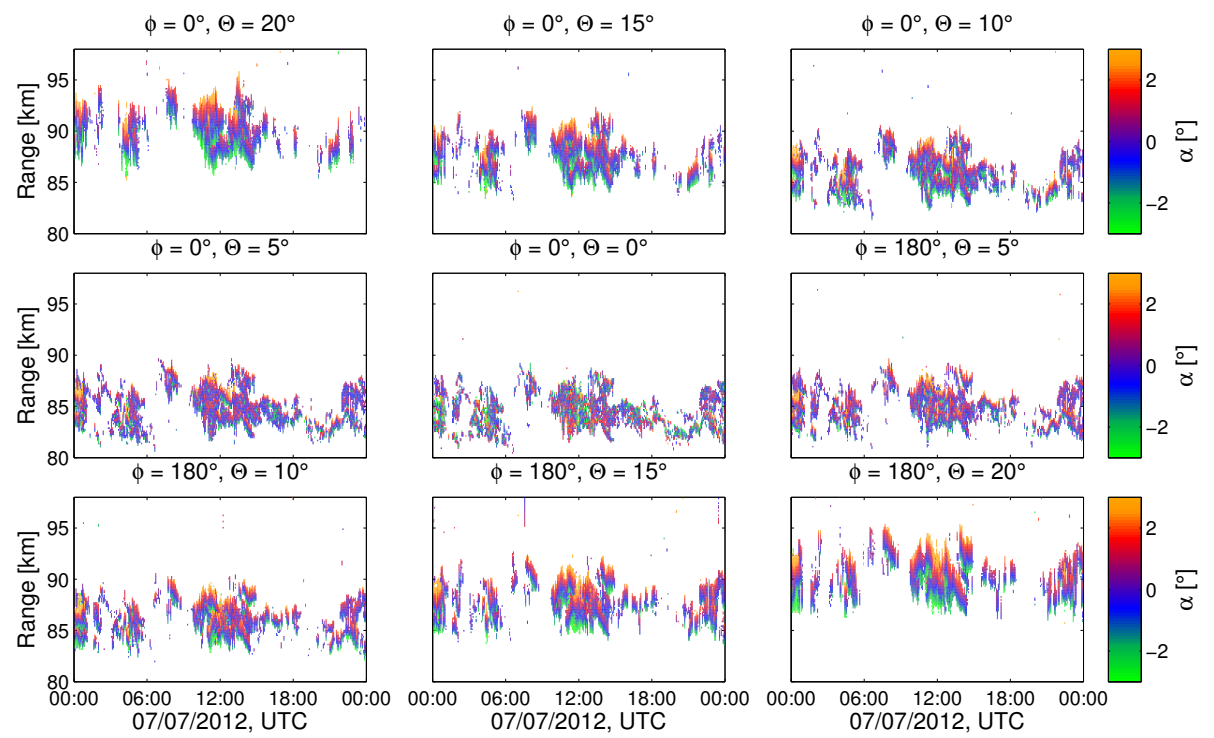

Figure 6. Same as Fig. 5, but with a scan from East to West.

part of the PMSE layer the mean backscatter location shifts downwards/upwards, indicated by positive/negative $\alpha$. The small deviations in the middle part of the PMSE region indicate that such regions are homogenously filled. No large deviation of the mean scatterer location from the nominal beam pointing direction.

\section{Conclusions}

Our PMSE observations applying CRI in tilted beams show a deviation of the mean scatter location depending on the tilt angle of the beam. To determine the mean backscatter loca- tion, we assumed a single center distribution and used the brightest pixel as a proxy of the mean backscatter location. Using tilted beams, sub-structures like small layers appear sometimes in oblique beams that cannot be seen in the SNR. This analysis might be used in the future to investigate the inner structures such as sub-layers on a higher spatial resolution.

Taking into account the smearing effect over height and also the fact, that the mean scattering center in the upper/lower part is less/greater than the beam pointing direction, we conclude that the radar volume of the tilted beam at the edge regions of PMSE is not homogenously filled. Only if the beam volume is homogenously filled, the deviation from 
the nominal off-zenith angle of the beam is around zero. As the beam volume is not totally filled at large off-zenith angles at the edges of the PMSE, the backscattered power is smaller compared to the vertical beam. Woodman and Chu (1989) suggest a scattering mechanism for turbulent atmospheric layers which are discrete over height. The sharp boundaries described in their layer model are consistent with our measurements, although they investigated echoes in the lower latitudes.

So far, we can not distinguish between a homogeneous filled beam volume and several thin layers. But in some cases, our method reveals sub-layers in tilted beams which are hard to detect using only the power as an indicator.

The deviation of the mean scatterer from the beam pointing direction should also be considered in wind calculations using PMSE as a tracer as already indicated by Stober et al. (2013). Using CRI to locate the scattering center can lead to better results since we showed that significant deviations of echo centers from the beam direction occur systematically at the PMSE edges. As Huaman and Balsley (1998) pointed out, the aspect sensitivity of PMSE has also to be taken into account for measuring the wind velocities, but our results indicate that this is only true at the lower and upper regions of the PMSE. The necessary corrections are more complicated and depend on the probed part of the PMSE layer and therefore alter with altitude and time.

Acknowledgements. The authors would like to thank Marius Zecha for MAARSY data handling and the Andøya Rocket Range for the support while building and operating the MAARSY radar and an anonymous reviewer for his/her helpful comments. The radar was built under grant 01 LP 0802A of Bundesmisterium für Bildung und Forschung.

\section{Edited by: M. Förster}

Reviewed by: C. Jacobi and one anonymous referee

\section{References}

Blix, T. A.: Small scale plasma and charged aerosol variations and their importance for polar mesosphere summer echoes, Adv. Space Res., 24, 537-546, 1999.

Chau, J. L., Renkwitz, T., Stober, G., and Latteck, R.: MAARSY multiple receiver phase calibration using radio sources, J. Atmos. Sol.-Terr. Phy., doi:10.1016/j.jastp.2013.04.004, 2013.

Chen, J.-S. and Furumoto, J.: Measurement of atmospheric aspect sensitivity using coherent radar imaging after mitigation of radar beam weighting effect, J. Atmos. Ocean. Tech., 30, 245-259, 2013.

Chen, J.-S., Hoffmann, P., Zecha, M., and Röttger, J.: On the relationship between aspect sensitivity, wave activity, andmultiple scattering centers of mesosphere summer echoes: a case study using coherent radar imaging, Ann. Geophys., 22, 807817, doi:10.5194/angeo-22-807-2004, 2004.

Chen, J.-S., Hoffmann, P., Zecha, M., and Hsieh, C.-H.: Coherent radar imaging of mesosphere summer echoes: Influence of radar beam pattern and tilted structures on atmospheric echo center, Radio Sci., 43, RS1002, doi:10.1029/2006RS003593, 2008.

Chilson, P. B., Yu, T.-Y., Palmer, R. D., and Kirkwood, S.: Aspect sensitivity measurements of polar mesosphere summer echoes using coherent radar imaging, Ann. Geophys., 20, 213-223, doi:10.5194/angeo-20-213-2002, 2002.

Czechowsky, P. and Rüster, R.: VHF radar observations of turbulent structures in the polar mesopause region, Ann. Geophys., 15, 1028-1036, doi:10.1007/s00585-997-1028-8, 1997.

Ecklund, W. L. and Balsley, B. B.: Long-term observations of the Arctic mesosphere with the MST radar at Poker Flat, Alaska, J. Geophys. Res.-Space, 86, 7775-7780, doi:10.1029/JA086iA09p07775, 1981.

Farley, D. T., Ierkic, H. M., and Fejer, B. G.: Radar interferometry: A new technique for studying plasma turbulence in the ionosphere, J. Geophys. Res.-Space, 86, 1467-1472, doi:10.1029/JA086iA03p01467, 1981.

Harding, B. J. and Milla, M.: Radar imaging with compressed sensing, Radio Sci., 48, 582-588, doi:10.1002/rds.20063, 2013.

Hocking, W. K., Ruster, R., and Czechowsky, P.: Absolute reflectivities and aspect sensitivities of VHF radiowave scatterers measured with the SOUSY radar, J. Atmos. Terr. Phys., 48, 131-144, 1986.

Huaman, M. M. and Balsley, B. B.: Long-term-mean aspect sensitivity of PMSE determined from Poker Flat MST radar data, Geophys. Res. Lett., 25, 947-950, 1998.

Hysell, D. L. and Chau, J. L.: Optimal aperture synthesis radar imaging, Radio Sci., 41, 1-12, doi:10.1029/2005RS003383, 2006.

Kudeki, E. and Sürücü, F.: Radar interferometric imaging of field-aligned plasma irregularities in the equatorial electrojet, Geophys. Res. Lett, 18, 41-44, doi:10.1029/GL008i004p00377, 1991.

Kudeki, E., Fejer, B., Farley, D., and Ierkic, H.: Interferometer studies of equatorial $F$ region irregularities and drifts, Geophys. Res. Lett., 8, 377-380, doi:10.1029/0GPRLA000008000004000377000001, 1981.

Latteck, R., Singer, W., Rapp, M., Vandepeer, B., Renkwitz, T., Zecha, M., and Stober, G.: MAARSY: The new MST radar on Andøya-System description and first results, Radio Sci., 47, RS1006, doi:10.1029/2011RS004775, 2012.

Palmer, R. D., Gopalam, S., Yu, T. Y., and Fukao, S.: Coherent radar imaging using Capon's method, Radio Sci., 33, 1585-1598, 1998.

Rapp, M. and Lübken, F.-J.: Polar mesosphere summer echoes (PMSE): Review of observations and current understanding, Atmos. Chem. Phys., 4, 2601-2633, doi:10.5194/acp-4-2601-2004, 2004.

Röttger, J. and Vincent, R. A.: VHF radar studies of tropospheric velocities and irregularities using spaced antenna techniques, Geophys. Res. Lett., 5, 917-920, 1978.

Sommer, S., Stober, G., Schult, C., Zecha, M., and Latteck, R.: Investigation of horizontal structures at mesospheric altitudes using coherent radar imaging, Advances in Radio Science, 11, 319325, doi:10.5194/ars-11-319-2013, 2013.

Stober, G., Latteck, R., Rapp, M., Singer, W., and Zecha, M.: MAARSY-The new MST radar on Andøya: First results of spaced antenna and Doppler measurements of atmospheric winds in the troposphere and mesosphere using a partial array, Ad- 
vances in Radio Science, 10, 291-298, doi:10.5194/ars-10-2912012, 2012

Stober, G., Sommer, S., Rapp, M., and Latteck, R.: Investigation of gravity waves using horizontally resolved radial velocity measurements, Atmos. Meas. Tech., 6, 2893-2905, doi:10.5194/amt6-2893-2013, 2013.

Sureshbabu, V. N., Anandan, V. K., Tsuda, T., Furumoto, J., and Rao, S.: Performance Analysis of Optimum Tilt Angle and Beam Configuration to Derive Horizontal Wind Velocities by Postset Beam Steering Technique, Geoscience and Remote Sensing, IEEE Transactions, 51, 520-526, doi:10.1109/TGRS.2012.2200256, 2013.
Woodman, R. F.: Coherent radar imaging: Signal processing and statistical properties, Radio Sci., 32, 2373-2391, 1997.

Woodman, R. F. and Chu, Y.-H.: Aspect sensitivity measurements of VHF backscatter made with the Chung-Li radar: Plausible mechanisms, Radio Sci., 24, 113-125, 1989.

Yu, T. Y., Palmer, R. D., and Hysell, D. L.: A simulation study of coherent radar imaging, Radio Sci., 35, 1129-1141, 2000.

Yu, T.-Y., Palmer, R. D., and Chilson, P. B.: An investigation of scattering mechanisms and dynamics on PMSE using coherent radar imaging, J. Atmos. Sol.-Terr. Phy., 63, 1797-1810, 2001. 